\title{
Hybrid Intelligent Control of Ceramic Shuttle Kiln Firing Temperature
}

\author{
Yonghong Zhu* and Yifeng Zhao \\ School of Mechanical \& Electronic Engineering, Jingdezhen Ceramic Institute, Jingdezhen, China,333403 \\ *Corresponding author
}

\begin{abstract}
For unstability and backward control method of ceramic shuttle kiln control system, a kind of hybrid intelligent control method of ceramic shuttle kiln is proposed in the paper. According to firing process of ceramic shuttle kiln, intelligent hybrid model of firing process for ceramic shuttle kiln was established. Firing temperature curve of a kind of ceramic products was obtained from the knowledge base of expert control system. In the meantime, Kalman filtering algorithm was given. Kalman filter-based PID hybrid intelligent controller was designed by combination of traditional PID control method with Kalman filtering method, so as to realize intelligent control of calcining zone temperature of ceramic shuttle kiln. In the end, MATLAB-based simulation results demonstrate the effectiveness and feasibility of the controller designed.
\end{abstract}

Keywords-ceramic shuttle kiln; limited state machine; expert system; PID hybrid intelligent control; kalman filtering

\section{INTRODUCTION}

Many kinds of ceramic products which are exported to other countries and regions have been produced in China every year. However, energy consumption of ceramic kilns is great in the production process, especially, the structure, combustion system, energy recycling and control system of ceramic kiln are relatively backward compared with some developed countries. Hence, the improvement of the thermal efficiency of kilns is regarded as a key research and development technology by the relevant departments in China .Ceramic shuttle kiln[1-4] is one of the most widely used modern intermitent kilns in the ceramic industry. It is widely used for sintering sanitary ware, ceramics for daily use, art ceramics and special ceramics. Its detection and control method directly affects the quality of ceramic products and energy utilization efficiency.

Ceramic shuttle kiln is a complicated plant with large time delay, strong nonlinearity and multi variable parameters. Temperature, atmosphere and pressure in it are influenced by many factors. Its production process is driven not only by continuous time signal but also by discrete event signal. Hence, it is a typical hybrid system. At present, the control mode of most ceramic shuttle kilns is semi-automatic control mode supplemented by artificial-look-fire. Relatively backward control method and unstable production seriously affect ceramic product quality, so it is necessary to study new control strategy to ensure the production stability of ceramic shuttle kiln.

In the industrial production process, the commonly used control method is PID control method[5-6]. It is effective to control the plant with small lag link by the traditional PID control method. But it is difficult to achieve the ideal control effect by using the traditional PID control for the nonlinear hybrid plant with pure lag link. Compared with other filtering algorithms, the Kalman filtering algorithm[8-10] is with a very strong error control ability and can control the track error in a very small range. Therefore, both the PID control method and the Kalman filtering method is combined to realize hybrid intelligent control of ceramic shuttle kiln firing temperature in the paper. So far, there is no report on the research on the application of the kind of control method to ceramic shuttle kiln. Based on the above situation, Kalman filter-based PID hybrid intelligent control method is proposed in the paper, and the simulation research on this kind of control method is also given. The simulation results demonstrate the effectiveness and feasibility of the control method proposed.

\section{THE ESTABLISHMENT OF FIRING PROCESS MODEL}

\section{A. Ceramic Shuttle Kiln Firing Process}

The adaptability of ceramic shuttle kiln to firing products is very strong, and its furnace temperature is affected by many factors. The firing products quality is largely determined by the firing process, hence, it is greatly relevant to the firing process temperature. Its main firing process includes low temperature stage, oxidation and reduction stage, high temperature stage and cooling stage. Specific firing process is as follows.

(1) Low temperature stage. This stage is generally below $400{ }^{\circ} \mathrm{C}$, and its temperature rise rate mainly depends on the thickness and moisture content of the billet body before entering the kiln. The moisture in the ceramic billet body is mainly removed at this stage. Too fast temperature rise rate may cause too large water vapor pressure in the billet body so that the billet body is cracked.

(2) Oxidation and reduction stage. The stage is generally form $400{ }^{\circ} \mathrm{C}$ to $900{ }^{\circ} \mathrm{C}$, and its temperature rise rate mainly depends on the mixing ratio of the clay, the flame nature and the airflow speed. The stage is porcelain forming stage. The amount of gas and oxygen can be increased, then the temperature in the kiln increases rapidly.

(3) High temperature stage. The final temperature of this stage depends on the type of ceramics, and its temperature rise rate depends on the kiln structure and the density of the loaded kiln. Too fast temperature rise rate in large kiln will lead to a large furnace temperature differences so as to result in different 
contraction of the billet bodies and the billet bodies deformation.

(4) Cooling stage. At the stage, fast cooling of cease-fire and slow cooling ventilation make the furnace temperature gradually decrease. Finally, ceramic products are got.

\section{B. The Acquisition of Firing Temperature Curve}

Expert control system is a kind of intelligent computer program which includes some special knowledge and practical experience given by some fields' experts. A specific expert system includes knowledge base, inference engine, working database, explanation machine, knowledge acquisition machine and user interface. The relationship among them is shown in Figure 1.

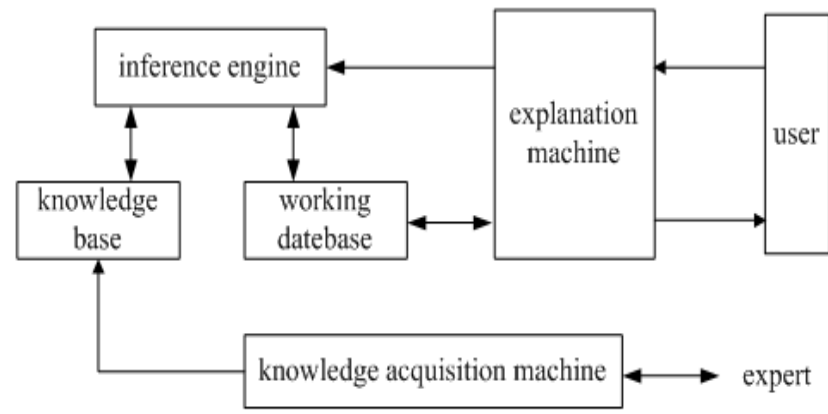

FIGURE I. EXPERT CONTROL SYSTEM

The knowledge base in the expert control system designed for ceramic shuttle kiln firing temperature contains a variety of firing temperature curves of ceramic sanitary ware, ceramics for daily use, art porcelain, special ceramics and so on in the paper. Specialized knowledge and data required in the field are stored in the knowledge base. Some data in the knowledge base of the expert system is obtained from the practical experience of the ceramic kiln experts. The knowledge base in the expert system mainly includes theoretical knowledge and practical experience. The working database is used to store the initial data and the data generated in the reasoning process. The inference machine is mainly used to memory the rules used so that the whole expert system can work in a coordinated manner. The interpretation machine is used to interpret the behavior of the expert system for users.

Due to different ceramics type, ceramics size, clay mix proportion, billet body thickness, water content of the billet body and ceramic kiln structure, the ceramic firing temperature curves are not the same. Therefore, these different factors constitute a wide variety of ceramic products. According to expert experience, their different firing temperature curves are stored in the knowledge base. Expert control system can be used to get more accurate firing temperature curve for a particular artistic porcelain. The firing temperature curve of some kind of ceramic product got by expert control system is shown as Figure 2. The firing temperature curve will be used for temperature reference input of ceramic shuttle kiln control system.

The template is used to format your paper and style the text. All margins, column widths, line spaces, and text fonts are prescribed; please do not alter them. You may note peculiarities.
For example, the head margin in this template measures proportionately more than is customary. This measurement and others are deliberate, using specifications that anticipate your paper as one part of the entire proceedings, and not as an independent document. Please do not revise any of the current designations.

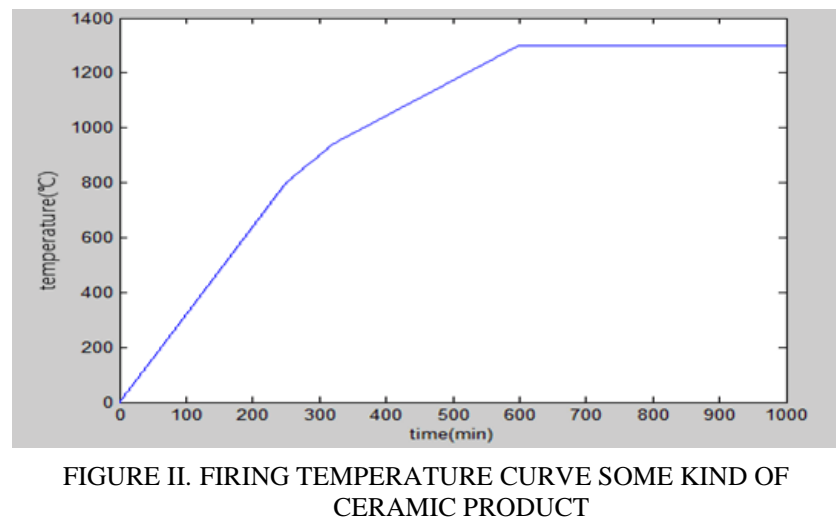

\section{Finite State Machine Modeling}

Finite state machine is a mathematical model for the transfer and action of the finite states when the event occurs. Therefore, the state change is driven by the event which can be external input signal or internal signal in the system, and the system can only be in one of the states at any moment. In ceramic shuttle kiln, the temperature rise process can be divided into work states of various stages, and the increasement of nozzle number one by one can also be regarded as external input signal in the temperature rise process, so the production process of ceramic shuttle kiln is driven not only by time signal but also discrete event signal and can be modeled by the finite state machine.

A complete finite state machine design should include the design of 3 elements such as state, event and action The state is a pattern which is used to describe the event-driven system , it is changed between the activity and the inactivity based on the event and the condition. The event is an object which generates the action, that is, while the system receives the event, it can generate the corresponding action. The action is a part of the state conversion, which is performed based on the state activity, and indicates the state change.

In a finite state machine, the state transition event is provided with the convertible state to construct a state transition diagram by a transition condition from a state to another state. In stateflow[7], the state and state transition is the most basic element. Finite state machine diagram is shown as Figure 3. In Figure 3, C denotes “Condition”.

According to the characteristics of the above ceramic shuttle kiln firing process, ceramic shuttle kiln firing process is modeled by finite state machine. The system is roughly divided into two states, namely, the work state and stop state of ceramic shuttle kiln..The work state is parent state of three different temperature states such as High, Middle and Low. 'Low' denotes low temperature stage. 'Middle' denotes oxidationreduction stage. 'High' denotes high temperature stage. The system is modeled as shown in Figure 4 by using state-flow. 
Figure 4 is the stateflow model of some kind of ceramic shuttle kiln firing process. When the ceramic shuttle kiln is in working state, at first, four nozzles start working, it means, the kiln temperature is in low temperature stage. When the temperature reaches $800{ }^{\circ} \mathrm{C}$, the other two nozzles start working, and at the same time there are six nozzles working, it means, the kiln temperature is in oxidation reduction stage. When the temperature reaches $940{ }^{\circ} \mathrm{C}$, the last two nozzles start working, and at the same time the total eight nozzles work together, it means, the kiln temperature is in the high temperature stage.

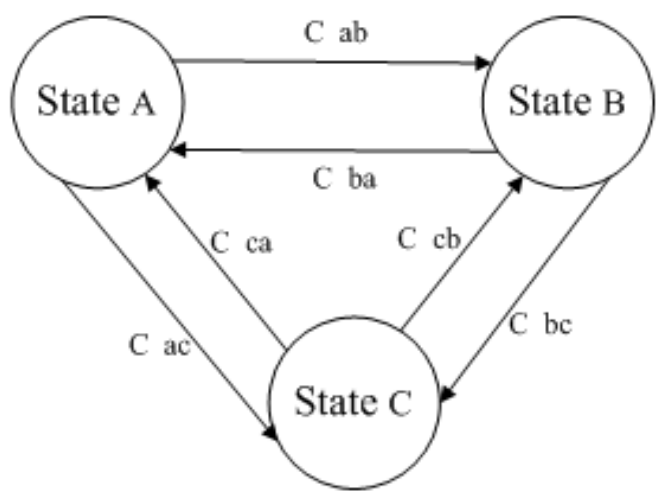

FIGURE III. SCHEMATIC DIAGRAM OF LIMITED STATE MACHINE

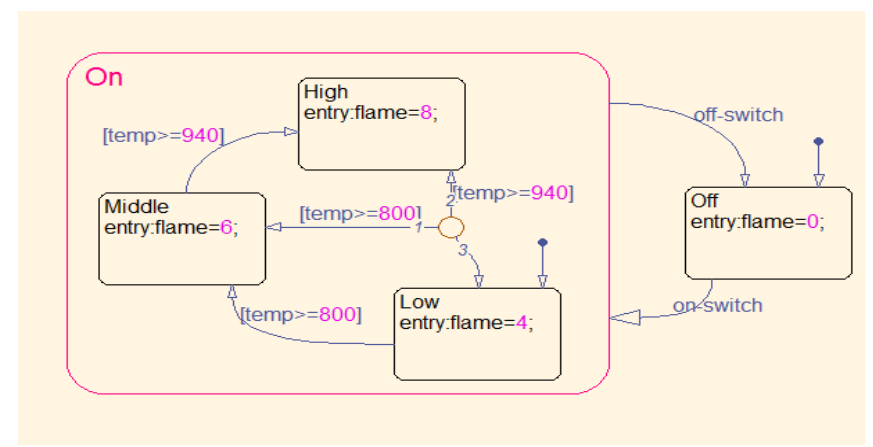

FIGURE IV. STATEFLOW MODEL

\section{CONTROLLER DESIGN}

\section{A. Digital PID Control}

The control law of PID analogue controller is as follows

$$
\mathrm{u}(\mathrm{t})=\mathrm{k}_{\mathrm{p}}\left[\mathrm{e}(\mathrm{t})+\frac{1}{T_{I}} \int_{0}^{\mathrm{t}} \mathrm{e}(t) d t+\frac{T_{D} e(t)}{d t}\right]
$$

where, the function of proportional link is to accelerate the response velocity of the system. If there are system errors, the errors can be reduced by the controller. The function of integral link is to eliminate the steady state errors of the system. The function of differential link is to improve the dynamic characteristics of the system, to accelerate the response velocity of the system, and to reduce the adjustment time.
In computer control system, it is necessary to discretize analogue PID controller to get digital PID controller. Substituting continuous time t with sampling time KT, integral with the numerical integral of the rectangular method, and differential with one order backward difference, we can get equations as followas.

$$
u(t) \approx u(K T) \quad(k=0,1,2, \cdots)
$$

$$
e(t) \approx e(K T)
$$

$$
\begin{gathered}
\int_{0}^{t} e(t) d t \approx T \sum_{i=0}^{k} e(i T) \\
\frac{d e(t)}{d t} d t \approx \frac{e(k T)-e[(k-1) T]}{T}
\end{gathered}
$$

Substituting the above equations (3)-(5) into equation (1), we can get the position control algorithm of digital PID as:

$$
\begin{aligned}
u(k T) & =k_{p}\left\{e(k T)+\frac{T}{T_{I}} \sum_{i=0}^{k} e(i T)+\frac{T_{D}}{T}[e(k T)-e[(k-1) T]]\right\} \\
& =k_{p} e(k T)+k_{i} \sum_{i=0}^{k} e(i T) T+k_{d} \frac{e(k T)-e[(k-1) T]}{T}
\end{aligned}
$$

where, $k_{i}=k_{p} / T_{I}, k_{d}=k_{p} T_{D}$. T is sampling period, $\mathrm{k}$ is sampling order number, $e(k T)$ is error signal at $t=k T$. In the application process, the coefficient of Equation (6) must be adjusted .

\section{B. PID Hybrid Intelligent Control Based on Kalman filter}

Considering process noise and measurement noise, the general model of linear discrete system is

$$
\begin{aligned}
& x(k)=A(k) x(k-1)+B(k)[u(k)+w(k)] \\
& y_{v}(k)=C(k) x(k)+v(k)
\end{aligned}
$$

where, $x(k)$ is estimated state variable at KT, $y_{v}(k)$ is observation variable, $A(k)$ is state transition matrix, $B(k)$ is noise input matrix, $C(k)$ is measurement matrix, $w(k)$ is process noise, and $v(k)$ is measurement noise.

In view of the above model, the recursive formula of the Kalman filter is as follow. 
Estimated covariance:

$$
p(k)=A(k) P(k-1) A^{T}(k)+B(k) Q(k-1) B^{T}(k)
$$

Filter gain:

$$
M_{\mathrm{n}}(k)=P(k) C^{T}(k)\left[C(k) p(k) C^{T}(k)+R(k)\right]^{-1}
$$

Mean square error matrix :

$$
P(k)=\left[I-M_{n}(k) C(k)\right] p(k)
$$

Optimal estimation of state variables :

$$
\hat{x}(k)=A(k) \hat{x}(k-1)+M_{n}(k)\left[y_{v}(k)-C(k) A(k) \hat{x}(k-1)\right]
$$

Error covarianc is

$$
\operatorname{err} \operatorname{cov}(k)=C P(k) C^{T}
$$

where, $Q(k)$ is observation noise covariance, $R(k)$ is measurement noise covariance, $I$ is unit matrix.

Based on Equation (8)-(12), we can get the following Kalman filter algorithm.

(1) Calculating initial state $x(0)$

Initial state can be obtained from the system. Assuming its estimated value as the expected value, that is, $x(0)=E[x(0)]$

From $p(0)=E\left\{[x(0)-\hat{x}(0)][x(0)-\hat{x}(0)]^{T}\right.$, we can get $p(0)=\operatorname{var}[x(0)]$.

(2) Calculating $p(1)$ and $M_{n}(1)$

$$
\begin{gathered}
p(1)=A(1) P(0) A^{T}(1)+B(1) Q(0) B^{T}(1) \\
M_{\mathrm{n}}(1)=P(1) C^{T}(1)\left[C(1) p(1) C^{T}(1)+R(1)\right]^{-1}
\end{gathered}
$$

(3) Calculating the optimal estimate

$$
\hat{\mathrm{x}}(1)=A(1) \hat{x}(0)+M_{n}(1)\left[y_{v}(1)-C(1) A(1) \hat{x}(0)\right]
$$

(4) Calculating mean square error matrix $P(1)$
According to the known $p(1)$ and $M_{n}(1)$, we can get $P(1)=\left[I-M_{n}(1) C(1)\right] p(1)$.

(5) Repeating (2), (3) and (4)

we can get the best estimate $\hat{x}(k)$ at any time.

(6) I $\mathrm{n}$ the end, utilizing $y_{e}(k)=C(k) \hat{x}(k)$, we can get output value $y_{e}(k)$ of each moment.

The PID control system structure of the ceramic shuttle kiln based on Kalman filter is shown as Figure 5. The temperature reference input rin of the system is got by the expert control system designed in the paper. The digital PID controller and Kalman filter are combined to realize the firing temperature control of the ceramic shuttle kiln in Figure 5.

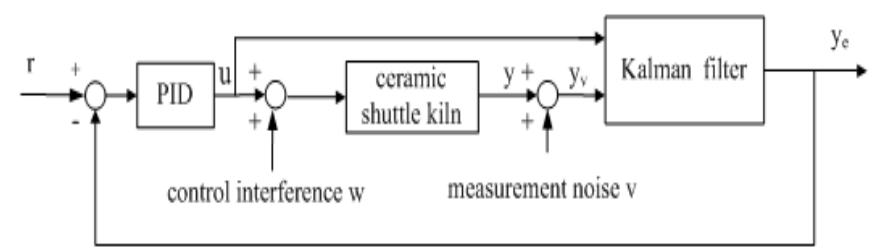

FIGURE V. PID CONTROL SYSTEM STRUCTURE BASED ON KALMAN FILTER

\section{SIMULATION}

Ceramic shuttle kiln is a complicated plant with large time delay, strong nonlinearity, multi variable coupling and variable parameters. Its reference model is

$$
G(s)=\frac{133}{s^{2}+25 s+1} e^{-15 s}
$$

Approximately discretizing the above plant model with process noise by using $\mathrm{Z}$ transform, we can get the discrete state space equation of the ceramic shuttle kiln control system as

$$
\begin{aligned}
& x(k+1)=A x(k)+B(u(k)+w(k)) \\
& y(k)=C x(k)
\end{aligned}
$$
is

The output of the controlled plant with measurement noise

$$
y_{v}=C x(k)+v(k)
$$

where, $A=\left[\begin{array}{cc}1 & 9.876 e-04 \\ 0 & 0.9753\end{array}\right], B=\left[\begin{array}{c}6.5949 e-05 \\ 0.1314\end{array}\right], C=[1,0]$. The Amplitude of both control interference signal $w(k)$ and measurement noise signal $v(k)$ are 0.002 white noise signal. 
Choose the covariance of $w(k)$ as $Q=1$ and the covariance of $v(k)$ as $R=1$.

By MATLAB simulation, we can get firing temperature curve of PID control-based ceramic shuttle kiln shown as Figure 6.

It can be seen from Figure 6 that the overshoot of firing temperature response curve is large and the adjustment time is longer. In order to reduce the overshoot and to improve the temperature control effect, both Kalman filter method and PID control method are combined to control the firing temperature of ceramic shuttle kiln. Based on MATLAB simulation, the firing temperature curve of the ceramic shuttle kiln by using PID control based on Kalman filter is shown as Figure 7.

The dotted line in Figure 7 is the firing temperature curve obtained by using PID control based on Kalman filter. From the simulation curve, it can be seen that the system is with smaller overshoot, shortened adjustment time and good robustness. The simulation results show that the PID control effect based on Kalman filter is better than pure PID control effect.

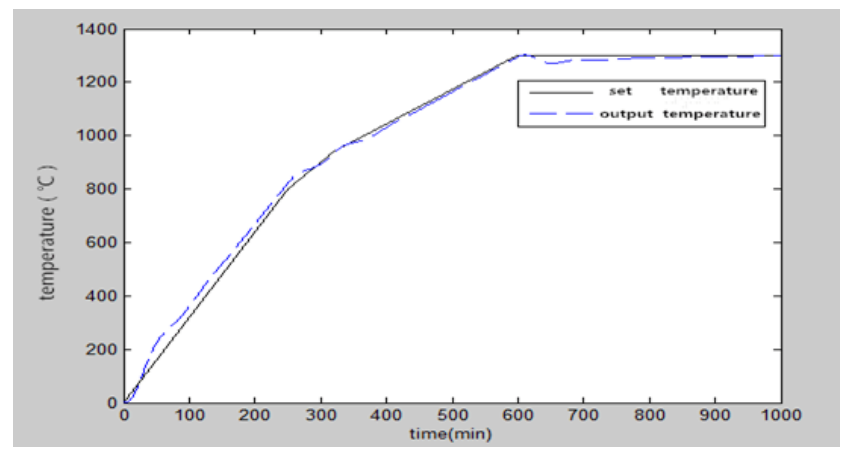

FIGURE VI. FIRING TEMPERATURE RESPONSE CURVE BASED ON PID CONTROL

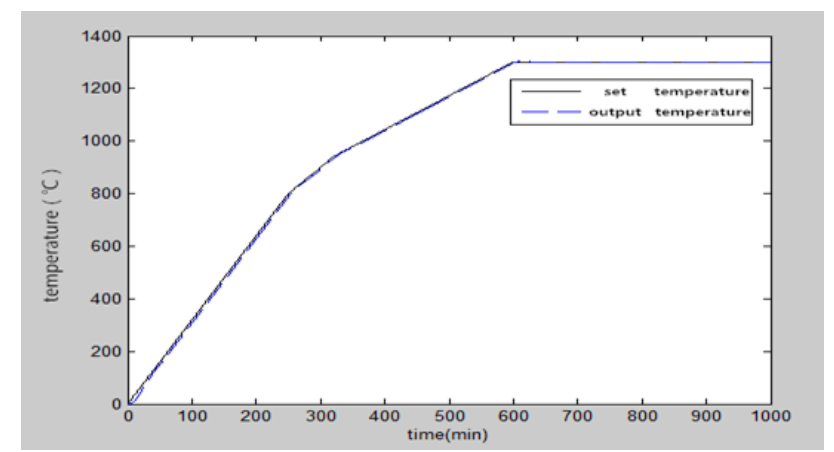

FIGURE VII. FIRING TEMPERATURE RESPONSE CURVE BASED ON PID CONTROL WITH KALMAN FILTER

\section{CONCLUSION}

The firing process of ceramic shuttle kiln is modeled by using finite state machine, and the firing temperature curve of ceramic shuttle kiln is obtained by using the expert control system. Kalman filter-based ceramic shuttle kiln hybrid PID control method is proposed by combining expert control system and PID control based on Kalman filter, and at the same time
Kalman filtering algorithm is given. In the end, For the model of ceramic shuttle kiln, Kalman filter-based PID hybrid control method is used to control the firing temperature of ceramic shuttle kiln. The simulation results show that Kalman filterbased PID hybrid control method is better than the pure PID control method. This control method will provide a theoretical basis for the effective control of ceramic shuttle kiln process and is with important application value. It will provide new method for intelligent temperature control ceramic shuttle kiln.

\section{ACKNOWLEDGMENT}

This work was financially supported by the National Natural Science Foundation of China (No. 61563022 and No. 61164014) and Jiangxi Province Natural Science Foundation of China (No. 20152ACB20009).

\section{REFERENCES}

[1] R.Saidur, M.S. Hossain, M.R. Islam, H. Fayaz and H.A. Mohammed, "A Review on Kiln System Modeling", Renewable and Sustainable Energy Reviews, Vol.15, pp.2487-2500,2011.

[2] Y. Jiang, "Research on Adaptive Control System of Shuttle Kiln Based on Fuzzy Neural Network”, Mechanical Design and Manufacturing (Chinese), Vol.9, No.9, pp.60-65, 2011.

[3] H. S. Li, Q. Miao and R. M. Zhou, "Research on Control Algorithms of Ceramic Kiln Temperature Control System', Journal of Wuhan University of Technology(Chinese), Vol.36, No.10, pp.135-139,2014.

[4] N. Q. Dinh and N. V. Afzulpurkar, "Neuro-fuzzy MIMO Nonlinear Control for Ceramic Roller Kiln”, Simulation Modelling Practice and Theory, Vol.15, pp.1239-1258,2007.

[5] Y. Wu, H. Jiang and M. Zou, "The Research on Fuzzy PID Control of The Permanent Magnet Linear Synchronous Motor”, Physics Procedia, Vol.24, pp.1311-1318, 2012.

[6] D. Q. Shi, G. L. Gao, Z. W. Gao and P. Xiao, "Application of Expert Fuzzy PID Method for Temperature Control of Heating Furnace”, Procedia Engineering, Vol.29, pp.257-261,2012.

[7] S. W. Hou, H. M. Zhu, R. Q. Li and S. R. Tong, "Stateflow Method for Abnormal Quality Diagnosis in Manufacturing Process”, System Engineering Theory and Practice(Chinese), Vol.33, No.3, pp.733-740, 2013.

[8] G. Evensen, "The Ensemble Kalman Filter: Theoretical Formulation and Practical Implementation”, Ocean Dynamics, Vol.53, pp.343-367,2003.

[9] H. Y. Du, Y. L. Hao and Y. X. Zhao, "SLAM Algorithm Based on Fuzzy Adaptive Kalman Filtering”. Journal of Huazhong University of Science and Technology(Nature Science Edition)(Chinese), Vol.40, No.1, pp.58-62, 2012.

[10] Dahir H. Dini, Danilo P. Mandic and Simon J. Julie, “A Widely Linear Complex Unscented Kalman Filter”, IEEE Signal Processing Letters, Vol. 18, No.11, pp.623-626, 2011. 